\title{
An Applicable Conception of e-Commerce in Provisions Support
}

\author{
De-Fu He* ${ }^{*}$ Xiao-Ling He, Yong Kang \\ Department of Quartermaster \& Purchase, Logistics Academy, Chongqing, China. \\ * Corresponding author. Tel.: 13886147238; email: hedefu1023@sina.com \\ Manuscript submitted April 28, 2017; accepted September 24, 2017. \\ doi: 10.17706/ijeeee.2018.8.2.97-104
}

\begin{abstract}
As e-commerce changes our living style, it will surely have a revolutionary impact on logistics support. In order to apply e-commerce technology to provisions support, several aspects should be emphasized when establishing an e-commerce platform: a network platform linking military and non-military users; an information publishing system; an identity authentication system; business management database; and the use of joint operation. Furthermore, provisions support process involves online ordering, merchant confirming, invoice transaction and financial settlement.
\end{abstract}

Key words: Provisions support, e-commerce, application.

\section{Introduction}

The essence of e-commerce means that producers have a direct relation with customers [1], [2]. In other words, with the orientation of supply chain and logistics distribution, e-commerce can make the distance between companies and users nearer by strengthening information system and logistics distribution, as well as reducing any intermediate links. Under the current circumstance of e-commerce, military provisions support can be described as the following procedure: shopping goods on e-commerce websites via network; generating new orders; then materials will be delivered to every unit via the warehouse, logistics and distribution systems of e-commerce enterprises [3], [4]. Because the materials circulation of e-commerce has the characteristics of quick response, functional integration and service serializing, operation standardization and target systematization have been achieved in the area of material allocation and delivery. In this case, it is surely necessary to build an e-commerce support model in the military forces that would combine military warehouse logistics and local supplies and realize organizational supply, relying on the current warehousing logistics network of big local e-commerce enterprises and the current military depots and logistics strength. Therefore, an E-commerce based on integrated logistics network is formed, which would make the distribution of provisions more convenient and easier, quicker and more efficient. Thusthe quick response of materials circulation would come true. During wartime, we can use the big data of peacetime supplies transportation information to predict the needs of combat troops in order to realize initiative distribution. We can use less inventory and agile circulation ways and initiatively deliver provisions materials to combat troops anytime and anywhere.

\section{The Necessity of E-commerce Application in Provisions Support}

\subsection{Low Procurement Benefit of Provisions Materials}


For most provisions materials, decentralized procurement is adopted, especially poultry, fishes, meat, eggs, fruits and vegetables which are unlikely to establish the unified purchase for the whole military forces or one theater due to their short shelf life and storage life, with the exception of the bidding and procurement of the whole military forces for provisions equipment and military food. Since 2013, the military has autonomously explored regional joint procurement, which has obtained certain effects. However, in general, supplies procurement still has certain problems. Insufficient competition can not lead to the result of purchasing good qualified but cheap supplies. However, as an open platform, E-commerce can make full use of network advantages to allow the information exchange of commodity supply and demand between the military and local market more quickly. On the one hand, using E-commerce way to purchase provisions materials, along with a transparent and competitive market environment, provides the military an opportunity to choose various suppliers, thus solving the problem of a single supplier. On the other hand, we can lower the cost of raw materials to support the military forces and save the spending of funds by the way of comparing the suppliers' product price and quality on the net to choose better materials and use the advantages of military group procurement for the initiative of trade [5].

\subsection{Cumbersome Procedures of Provisions Materials Support}

To manage provisions materials better, the offices of the Central Military Commission formulate a series of related materials purchasing and supply system. Life service center uses materials storage, processing and supply system, together with the system of publishing the accounts. Mess units have the inspection and storage system of incoming materials, daily consumption registration system, as well as account records and food publishing system. The implementation of the systems is of great significance for avoiding the "Pao Mao Di Lou (leakage) " of the cost [6]. But, with a piece of paper "copied" again and again, it actually causes a lot of trivial formalities, which naturally takes up a lot of time. Of course, the efficiency is not high in this circumstance. Therefore, some forces have not implemented these systems any longer now, especially in a time when the whole military forces vigorously lay great emphasizes on training, winning and downsizing. Obviously, the application of E-commerce, network or the technology of two-dimensional bar code can make electronic data exchange come true, significantly reduce repetitive labor and simplify support procedures.

\subsection{Deficient Means of Provisions Materials Supervision}

The current purchasing and management of provisions materials at primary-level lacks an effective supervision system. From the perspective of systems, both staple and non-staple food is purchased by business departments, life service centers and mess units together. Here involves both cooperation and supervision. However, from the perspective of operation, it is difficult to form a resultant force between different departments. Market purchasing invoicesare also hard to obtain. To some extent, the following phenomena sometimes do exist: handwriting is not clear on invoices; weighing is often not accurate; Writing false invoices with less value and selling shoddy goods. However, with the comprehensive use of E-commerce technology and network resources, the purchasing and supply of military provisions materials can be uniformly planned. The planning, distribution, storage, supply and consumption of provisions materials can be operated by network. So the business data and expenditure among mess units, life service centers and suppliers will be fully transparent, which will be more conveniently for commanders, the vast majority of officers and soldiers, and business offices at various levels to supervise mess expenses, along with the storage and retrieval of materials. This practice will surely ensure that "all can speak out about and all can participate in the management of" provisions support.

\section{The Construction of e-Commerce Platform for Provisions Support}


With the popularity of networks and the establishment of joint logistics system, the communication between offices and troops becomes much closer and information exchange is more frequent, which provides sufficient conditions for the construction of E-commerce in the military. At the same time, civil E-commerce is booming, thus the technology is already very mature now, which also guarantees for the construction of military provisions E-commerce platform. Therefore, as an intermediation, E-commerce can provide a large number of purchasing information of provisions materials, personalized services and integrated portal services, which allows the military forces to have extensive purchase options. In the meantime, provisions departments can actively contact with suppliers, which makes electronic commerce and provisions materials purchase more seamless. At the same time the platform provides the service of big data. With this technique, information flow, cash flow and logistics can be integrated into an E-commerce supply chain, which infiltrates into supplier management, materials procurement management, the supervision of mess quality and living standard, as well as other key links [7].

Provisions support E-commerce platform is as shown in Fig. 1.

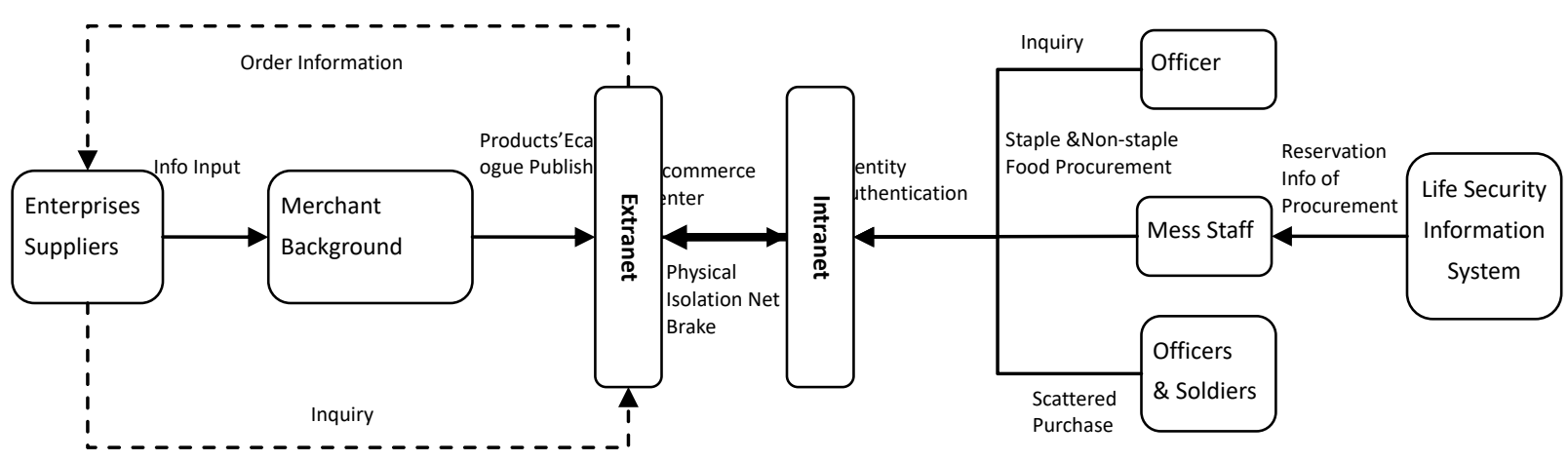

Fig. 1. Provisions support e-commerce platform.

\subsection{Establishing a Network Platform Connecting Both the Military and the Civil Network}

To construct the electronic commerce platform between military provisions support agencies and enterprises, an Intranet should first be created to connect the military internal Wide Area Network for all the provisions materials procurement operations in every military unit. Then an extranet should be established to outreach domestic Internet for the staple and non-staple food procurement in domestic market. Net brake isolation technique can be used in the area of the data exchange between the two nets [8] It is a physical isolation technology, using physical net brakes to connect two independent host systems with the reading and writing medium of solid-state switch of a variety of control functions, which provides an environment of network security for both the armed forces and suppliers to transact. The Intranet can be based on military web platform and we can also use tablets or mobile phones to connect Intranet. A variety of patterns should be designed for the convenience of officers and soldiers to buy.

\subsection{Establishing an Information Publishing System of Provisions Support}

Military information publishing system for E-commerce platform includes two aspects: one is to build a multiple data sharing network service station (merchants), specifically to provide the virtual host and server hosting service for suppliers, which comprises of commodity management, sales promotion, order management, distribution, and other functions, so it is not only convenient for settlement center and suppliers to exchange data, but also much safer and more secured. Enterprises or suppliers release raw materials or commodity information in the background and information platform is responsible for 
receiving and converting the information, which means that local materials can have an indirect role in military provisions operation. The second is to connect the data between management information system of mess units and military life security data servers. Each mess unit uses the system to develop a week recipe and submit the original data to military life security data servers to complete the material booking submission. The ordering personnel of life service center choose and purchase the staple and non-staple food required by each mess unit according to the procurement and processing plans in E-commerce Intranet platform.

\subsection{Establishing an Identity Authentication System}

The platform provides different entries for identity authentication. Each time, users must enter their own unit codes, allocated private passwords, along with other information to authenticate successfully. The responsible officers of each element and business office can enter the platform and inquire related data to supervise the procedure; kitchen administrator can get access to the platform and buy the staple and non-staple food to improve mess management; soldiers can also pass into the platform to purchase snacks and dairy products in the peacetime, which satisfies the purchase needs of officers and soldiers and enhances military service quality.

\subsection{Establishing a Database for Provisions Management}

The provisions support e-commerce database and repository is shown in Fig. 2.

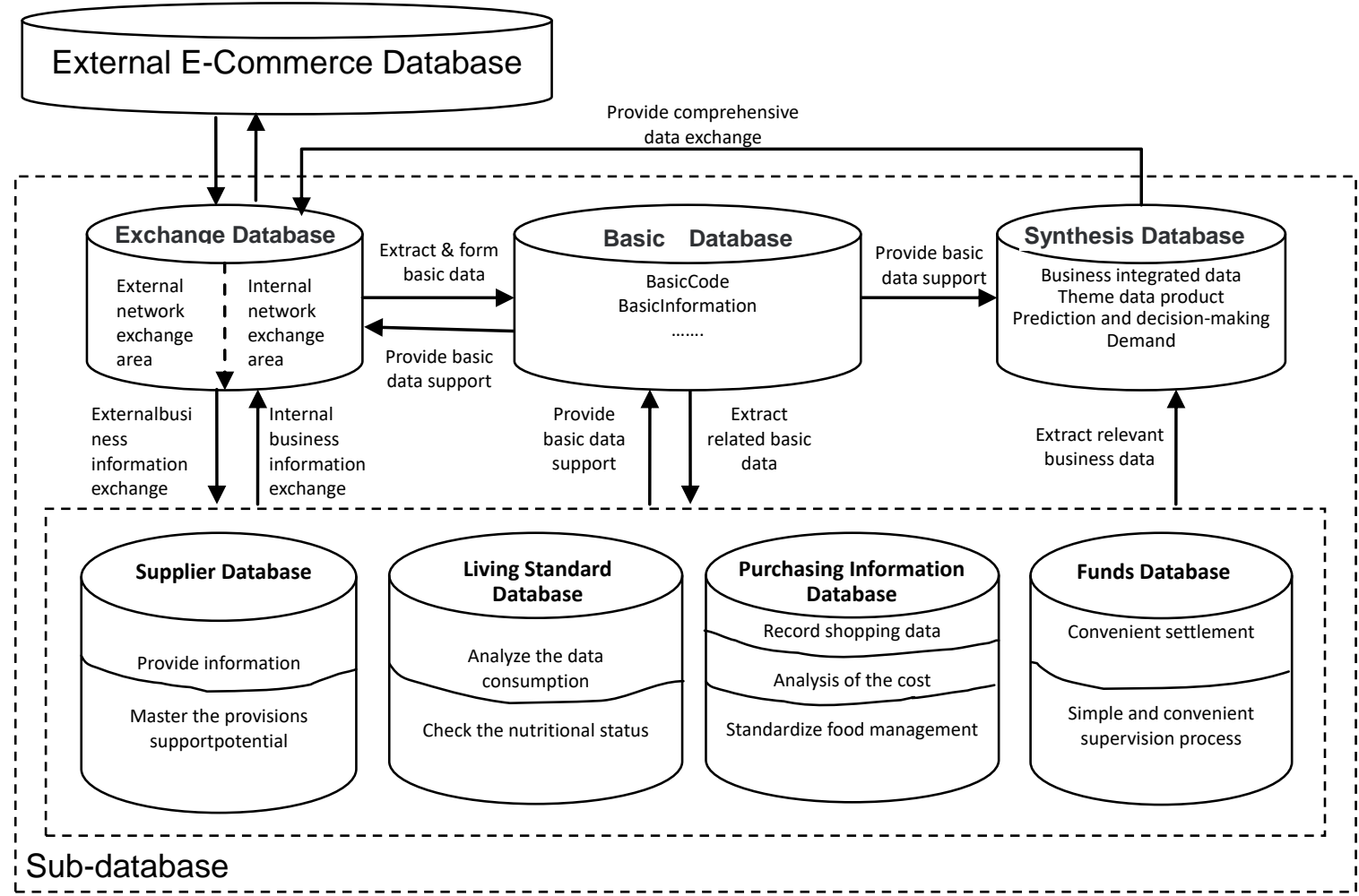

Fig. 2. Provisions support e-commerce database.

The internal part of the platform sets up a database by using Oracle or domestic database management system. The information is managed and integrated by Bureau of Quartermaster and Energy [9]. The database mainly consists of four parts. The first is supplier database that is used to accumulate relevant suppliers' information, which not only provides information for provisions department to raise materials, but also is convenient for the military to master the provisions support potential nationwide. The second is 
living standard database, which comes from the daily consumption registration data of mess unit management system. Via this database, mess units can be selected for the analysis of nutrients per capita consumption data of a certain period of time and the nutritional status of officers and soldiers can be monitored. The third is purchasing information database. It is to record military shopping data on the platform in the peacetime. The platform can analyze the use of food expenses in the military forces and standardize the management of food quality. The last is funding database that has accounting records and can automatically generate certificates, together with other functions. Recording the accounting in the database is more convenient for the settlement between suppliers and the military forces, which is also easier for supervising the working process. And relevant business authority can directly inspect and supervise in the database.

\subsection{Invoice Transaction}

When the advance payment of the purchaser is received by the electronic commerce center (settlement), the center is responsible for notifying the merchant to deliver goods [10]. Only after the buyer receives the goods, the center will make the full payment for goods to the merchant. In case of refund or exchange, the center will deposit the advance payment as a security, which is guaranteed with its own reputation. Only when the after-sales service process is completed, the center will return the advance payment. In general, the platform will find the third party logistics or the military logistics system to distribute the products to ensure that the center can receive the information timely after the buyers receive the products.

\subsection{Financial Settlement}

The platform sets up payment and settlement modules. And relying on the online banking payment system, the platform can research and develop a kind of purchasing card for electronic commerce provisions support, which can be linked up to the military financial system. Via payment and settlement modules, the variety, quantity and amount of purchasing materials, as well as the information of suppliers will all be collected and imported into the purchasing card. Purchasing staff would acquire payment password from financial department [11]. Thus, the military units just input payment password when receiving the products. Upon the receipt of goods, the platform can automatically make the payment for goods to merchants to close the transaction.

The E-commerce procurement process of provisions support is shown in Fig. 3.

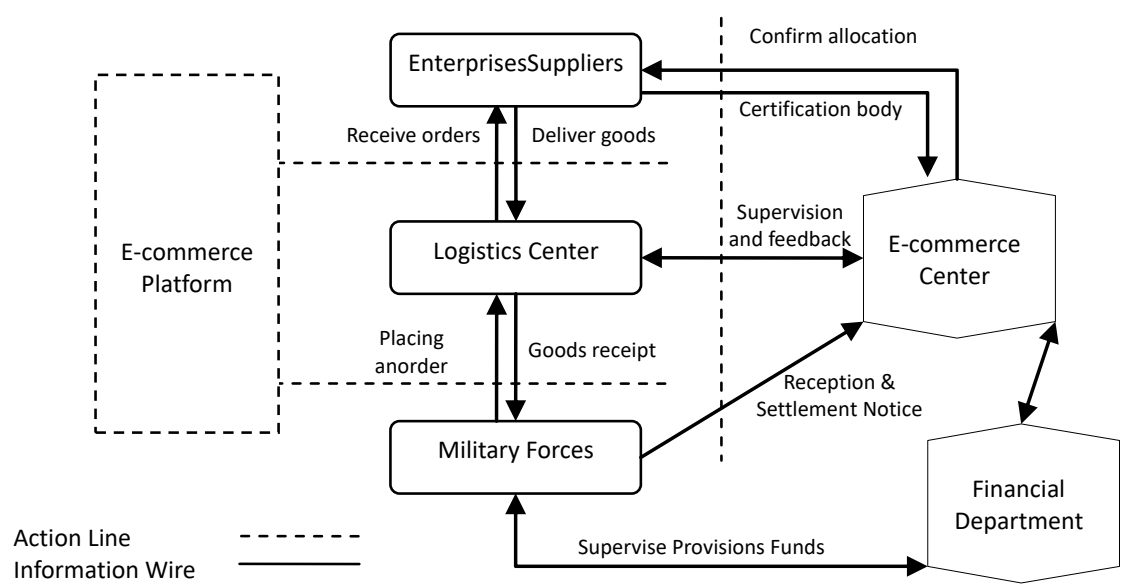

Fig. 3. E-commerce procurement process of provisions support. 


\section{Problems and Solutions}

\subsection{Changing the Thinking Mode of Officers and Soldiers}

E-commerce provisions support platform is a new systems engineering, which requires everyone's active participation. But some personnel from the provisions industry are not familiar with this and they do not accept or even resist it because they are worried about making mistakes. Only by changing their thinking modes to accept the procurement method of provisions materials under the circumstances of e-commerce provisions support platform, can the platform be implemented. It also can improve the creativity of provisions work in E-commerce environment and accelerate the process of provisions support informatization. Military forces can guide provisions staff by conducting E-commerce theoretical education and make them aware of the importance of conducting E-commerce in provisions work. And it is essential to establish corresponding E-commerce learning institutions and formulate rewards and punishment measures to stimulate the enthusiasm of provisions staff to use E-commerce.

\subsection{Preparing for the Transition from Peacetime to Wartime}

Using suppliers' database, provisions staff can select the appropriate suppliers and sign strategic agreements with them, then supplier information is input to "the wartime E-commerce platform". The platform automatically generates the orders for provisions materials during the war. It will estimate the requirement for war provisions materials according to the data and information in the peacetime. Local suppliers will be converted to the mobilization strength of national defense economy, which provides support for war materials. This rapid transformation of peacetime and wartime platform can make suppliers prepare strategic reserves ahead, predict the demand by using the system programs, and automatically complete the orders, which greatly improve the speed and efficiency of wartime provisions supplies.

\subsection{The Security of e-Commerce}

Since provisions support requires a high degree of security itself as a military activity, under the condition of electronic commerce, provisions support naturally needs to have a safe environment of computers and networks, mainly including: the security of traders' identity, irrevocable transaction documents and the rigor of the Intranet. To ensure that electronic commerce platform can run under a safe environment, it first needs to adopt the technology of visitor identity authentication, data encryption and firewall to strengthen safety control. It also can use gradually mature digital signatures and PKI technology to ensure the security of E-commerce procurement. Next, it also needs to improve the management of electronic commerce provisions support platform from information security management institutions in order to ensure the security of network transactions since security technology and equipment alone are not enough.

\subsection{The Security Problems of Military Barracks Caused by Logistics}

The logistics distribution under the condition of electronic commerce is the important branch of trading activity. Because the third party logistics service providers are employed to distribute the products, the address and the location of barracks may be exposed. And in the meantime, since the whole distribution process is linked to the network, it is likely to cause barracks information on the Internet uncovered by foreign hackers and spies, which may seriously harm the safety of barracks. To solve this problem, two suggestions are offered here. One is the management of order information. The troops' order information only has order number, product number, unit code and collection point address, which does not involve sensitive information. The other is to require local enterprises to remove the orders from troops in the database at fixed period in order to prevent data mining. 


\subsection{Training e-Commerce Personnel}

To create the environment for E-commerce talents, it needs a group of talents who are proficient in provisions business and understand the technology of electronic commerce. The military should organize some learning activities of electronic commerce at ordinary times and some application training in various departments and mess units at different levels to constantly improve their levels of theory and practice. Talents exchange can be used at the same time. The excellent electronic commerce talents of local enterprises will communicate with military logistics E-commerce talents, which is beneficial for military personnel to have the most direct access to market information. It is also advantageous for military talents to build up skills in the fierce competition, which is useful when they are transferred to civilian work. It is still beneficial for military personnel to improve comprehensive quality. Therefore, both military and civilian provisions departments should speed up the training of electronic commerce talents and build up a highly qualified team of electronic commerce talents according to a systematic plan to provide talents guarantee for provisions work in the electronic commerce environment.

\section{References}

[1] Wan, Y., \& Zheng, B. (2002).The Influence and of e-commerce upon troops logistic construction and coping strategies. Military Economic Research, 12, 69-72.

[2] Wang, C. (2002). Application of e-commerce to troops material acquisition. Military Economic Research, 4.

[3] Xu, R. Y., et al. (2007). Application of e-commerce in troops life support. Military Economic Research, 7, 72-74.

[4] Xu, C., et al. (2012). The application of e-commerce in troops purchase of food support. Proceedings of International Conference on Engineering and Business management (pp. 3378-3380).

[5] Cai, Y. G., \& Li, T. H. (2004). Application and development of e-commerce in military material procurement. Journal of Military Economics College, 1, 21-24.

[6] Yu, C. X., \& Liu, Z. W. (2013). Concept of US Future Logistics. Beijing: Military Science Press.

[7] Sun, X., et al. (2011). The discussion of war material reserves strategy under information conditions. Logistics Sci-Tech, 2,112-114.

[8] Fu, L. Y., et al. (2016). Design and implementation of an across Netgap data transmission system. Computer\& Digital Engineering, 10, 1996-2000.

[9] Shen, Y. C. (2008). Research on Development and Strategy of E-Commerce in the Military Logistics. Wuhan: Central China Normal University Master Degree.

[10] Huang, X. J., \& Yao, H. X. (2006). Research on features of then US Army's e-commerce development. Logistics Sci-Tech \& Equipment, 5, 18-19.

[11] Yang, H. F. (2011). Application of e-commerce in quartermaster support. China Journal of Commerce, 14, 111-112.

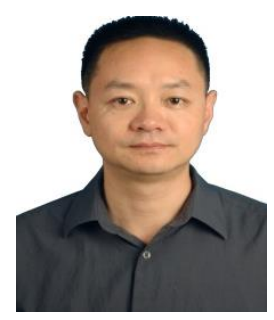

De-Fu He was born in Zaoyang city of Hubei province in China on October 23, 1976. He holds a doctor's degree of military science in Wuhan city of Hubei province in China in 2009.

He is currently engaged in teaching and research work in the Department of Quartermaster \& Purchase in ALA. And he has published more than 40 papers, including 5 books, including: A New Model for International Relationship Based on Multi-Agent, published in Multispectral Image Processing and Pattern Recognition (Guilin, China, SPIE, 2011); Research on Data Exchange Platform Based on JMS, published in 2016 2nd IEEE International Conference on 
Computer and Communications (Chengdu, China, IEEE, 2016); The Theory and Practice of Provisions Information Statistics and Monitoring. Military Science Press, 2015. At present, he mainly engages in quartermaster, logistics and informatization research.

Dr. He is a director of Systems Engineering Society of Hubei Province, an expert in logistics technology and equipment evaluation, and a master tutor in the field of Rear Special Services.

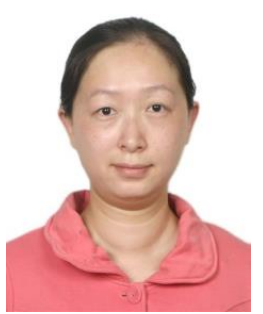

Xiao-Ling He was born in Jingshan of Hubei province in China on February 29, 1980. She holds a master's degree in foreign linguistics and applied linguistics from Wuhan University of Technology in China in 2005 where she also obtained bachelor's degrees in English and economics in 2002. And her major field of study is teaching English as second language and translation.

She is a lecturer for ALA in College English in Chongqing at present. Her recent article is titled Personalizing Independent Learning: An Applied Study on Military English Course Based on Flipped Classroom published by ILA Conference 2016 in Wuhan. She is currently interested in autonomous learning, CAI, flipped classroom, TESL and translation.

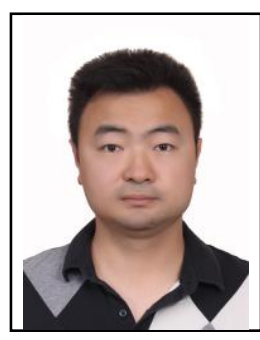

Yong Kang was born in Ganzhou city of Jiangxi province in China on July 21, 1984. He holds a doctor's degree of military science in Wuhan city of Hubei province in China in 2017.

He is currently engaged in teaching research work in the Department of Quartermaster \& Purchase in ALA. At present, he mainly engages in quartermaster, logistics and informatization research. 